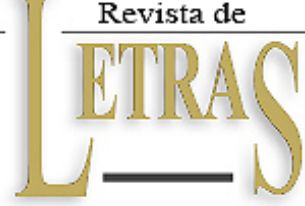

\title{
POR UMA TRADUÇÃO PERFORMÁTICA
}

\section{TOWARDS PERFORMANCE AS TRANSLATION}

\author{
Elizabeth Santos Ramos* Luana Lise Carmo da Solidade**

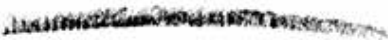

\section{RESUMO}

Este artigo busca fundar bases iniciais para o estabelecimento de um quarto tipo de tradução para além da tríade estabelecida por Roman Jakobson (1969). Através das noções de escritura, acontecimento e intempestividade, pretendemos propor que a performance é um mecanismo de tradução que ressignifica a conjuntura histórica na qual está inserida. Desse modo, o que aqui intitulamos de tradução performática implica a concepção da cena da performance como um processo tradutório. Ou seja, apontamos que, através da cena, a performance cria rasuras em discursos oficiais e em estruturas de ordenamento cronológico - aderindo e ao mesmo tempo tomando distância de seu tempo - marcando, pois, a intempestividade (Nietzsche, 2003) da tradução performática. Propomos, ainda, que o sujeito ativo da tradução performática é o performer-tradutor que, por meio das performances, constrói dispositivos para que se torne aquilo que é - no vazio da possibilidade de existência como sujeito ativo do mundo, as performances funcionam como formas estéticas e políticas de recriação de existência.

Palavras-chave: tradução performática, cena, conjuntura histórica.

\section{ABSTRACT}

This article seeks to consolidate initial bases for the establishment of a fourth type of translation beyond the triad established by Roman Jakobson (1969). Through the notions of writing, happening and the untimely, we intend to propose that performance is a mechanism of translation that re-signifies the historical conjuncture in which it is inserted. Thus, what we call performatic translation here implies the conception of the performance scene as a translation mechanism. That is, we point out that, through the scene, performance creates erasures in official discourses and in structures of chronological order - adhering and at the same time taking distance from its time -marking, therefore, the untimely (Nietzsche, 2003) character of the performatic translation. We also propose that the active subject of the performatic translation is the translator-performer who, through performances, constructs devices to become what he is - in the absence of an active subject of the world, performances function as aesthetic and political devices of recreation of existence.

Keywords: performatic translation, scene, historical conjuncture.

*Pós-Doutora pela Universidade de São Paulo. Mestre e Doutora em Letras e Linguística pela Universidade Federal da Bahia. Interessada nos Estudos da Tradução e nas representações da natureza humana na literatura.Professora Associada III no Departamento de Letras Germânicas e no Programa de Pós-Graduação em Literatura e Cultura da Universidade Federal da Bahia.Orcid: 0000-0001-7097-52152

**Mestra em Literatura e Cultura pela Universidade Federal da Bahia. Doutoranda em Literatura e Culturana Universidade Federal da Bahia.Investiga as relações entre tradução e performance atravésdo estudo dacanção enquanto gênero literário.Orcid: 0000-0002-9844-4157 


\section{SERÁ ARTE?(.)}

Uma parte de mim/ É só vertigem:/ Outra parte,/ Linguagem./ Traduzir-se uma parte/ Na outra parte/ — Que é uma questão/De vida ou morte — / Será arte?

\section{Ferreira Gullar - Traduzir-se}

Se o suporte teórico pós-estrutural no campo dos Estudos de Tradução rasura noções de equivalência, originalidade ou complementaridade na tarefa de traduzir, ele também nos dá a fundamentação para pensar o ato de traduzir como um acontecimento. De acordo com Ottoni (2005), no paradigma da desconstrução, a tradução constitui "acontecimento que deflagra a língua, está entre as línguas e faz parte das línguas." (OTTONI, 2005, p. 51), possibilitando-nos concluir que, enquanto acontecimento da linguagem, a tradução se configura como desconstrução, ou prática da diferença.

Ao desenvolver sua reflexão, Ottoni (2005) afirma ainda que "a prática da diferença só se efetiva na tradução se pensarmos não só na multiplicidade das línguas, mas também no que essa multiplicidade encena". (OTTONI, 2005, p. 19).Apoiando-nos na premissa da tradução como prática da diferença, que encenao movimento recíproco de "produção e transformação infinita de significados" (OTTONI, 2005, p.19), pretendemos ir para além da reciprocidade ou elo duplo presente entre as línguas. Buscamos aqui contemplar o caráter performático da cena da tradução, ou seja,tradução como acontecimento da multiplicidade, como estratégia que potencializa e é atravessada pelo performático. Dessa forma, performance torna-se o conceito-chave para a proposta de um quarto tipo de tradução para além da tríade estabelecida por Roman Jakobson (1969):

Distinguimos três maneiras de interpretar um signo verbal: ele pode ser traduzido em outros signos da mesma língua, em outra língua, ou em outro sistema de símbolos não-verbais. Essas três espécies de tradução devem ser diferentemente classificadas: 1). A tradução intralingual ou reformulação (rewor-ding) consiste na interpretação dos signos verbais por meio de outros signos da mesma língua. 2) A tradução interlingual ou tradução propriamente dita 'consiste na interpretação dos signos verbais por meio de alguma outra língua. 3) A tradução inter-semiótica ou transmutação consiste na interpretação dos signos verbais por meio de sistemas de signos não-verbais.(JAKOBSON,1969, p.64-65)

Deste modo, propomos pensar que, para além da tradução intraligual, interlingual e intersemiótica, o que intitulamos de tradução performática consistirá na articulação dos eixos espaço-tempo através do performático, ou seja: na tradução de uma conjuntura histórica ressignificada através da materialidade da cena na sua condição de acontecimento. Se a performance é uma arte para ser realizada em ato que denota um posicionamento político diante de uma conjuntura, propomos pensar a performance como gesto que traduz - em diferença - a história.

\section{PARA PENSAR A PERFORMANCE: ESCRITURA E DISSEMINAÇÃO}

Jacques Derrida (1991) nos indica as bases para pensarmos o performático a partir de uma nova concepção de escrita, a escritura ou a-escrever: agência transformadora que, através de uma rede de conexões, coloca em ação textos, sentidos, expressividades e corpos. Derrida (1991) desconstrói a ideia de escrita advinda de certa associação que toma o significado do termo comunicação apenas como veículo ou transporte de sentidos. Assim, a palavra comunicação pode instaurar significados que extrapolam os campos da semântica, da semiótica ou da linguística, perspectiva que nos permite concluir que o significante "comunicação" pode vir a gerar o que o filósofo francês chamou de movimentos não-semânticos: 
Aqui um recurso ao menos provisório à linguagem vulgar e aos equívocos da língua natural ensina-nos que se pode, por exemplo, comunicar um movimento ou que um abalo, um choque, um deslocamento de força pode ser comunicado - entenda-se propagado, transmitido. Diz-se também que lugares diferentes ou distantes podem comunicar entre si através de tal passagem ou tal abertura. $\mathrm{O}$ que se passa, então, o que é transmitido, comunicado, não são fenômenos de sentido ou de significação. Não se trata nesses casos nem de um conteúdo semântico ou conceitual, nem de uma operação semiótica, ainda menos de uma troca linguística. (DERRIDA, 1991, p. 349)

O movimento que Derrida (1991) opera é pensar a palavra comunicação não como um transporte ou veículo, mas como disseminação. Com efeito, o sentido se dissemina, por isso o choque, isto é, o abalo provocado em outros corpos pode ser entendido como comunicação. Entretanto, o acontecimento, como presença - o momento da enunciação, a materialidade, o gesto corporal ou a voz - não podem ser pensados como ponto de origem, pois pensar a comunicação "física" ou "real" como sentido próprio ou primitivo é ainda levar em consideração que a materialidade veicula uma verdade.

Além disso, Derrida (1991) rompe com a ideia de polissemia na comunicação - entendida como conversão de múltiplos sentidos - e reafirma a noção de disseminação: potência interpretativa que não transmite uma multiplicidade de sentidos, mas que, na ausência do sentido, propaga possibilidades de significação. A disseminação é o que ultrapassa os limites da escrita e nos leva a pensar a escritura, ou escrita enquanto processo.

Outro ponto de crítica trazido por Derrida (1991) acerca do conceito de comunicação é o limite traçado pelo ideal de contexto. Tal limite prescreveria uma espécie de consensus implícito para que as comunicações pudessem ser entendidas e envolvessem os diálogos numa linha de inteligibilidade e de uma verdade do sentido, de forma que um acordo geral pudesse ser estabelecido. Para Derrida (1991), entretanto, "um contexto nunca é absolutamente determinável; sua determinação nunca é assegurada ou saturada, o que assinala a insuficiência teórica do próprio conceito de contexto." (DERRIDA, 1991, p.351). A impossibilidade de determinação de um contexto gera um deslocamento do conceito de escrita, que não mais poderia ser entendida como comunicação, enquanto transmissão de sentido. Aumentando-se o campo de percepção do conceito de escrita, os efeitos da comunicação poderiam então ser pensados como "particulares, secundários, inscritos, suplementares" (DERRIDA, 1991, p. 351). Além disso, essa ampliação do conceito de escrita proposta por Derrida (1991) deita por terra a organização do sistema representacional, pois o conceito de representação é indissociável dos de comunicação e de expressão: a estrutura representativa marcaria o primeiro grau da comunicação expressiva, a relação ideia/signo.

A estrutura representacional do pensamento, ou a noção de escrita como presença, como essência do texto (ideia, intenção, sentido, conteúdo), é o limite pensado por Derrida (1991) a partir da estrutura da dialética de Hegel (tese, antítese, síntese):

A tese e a antítese e a sua demonstração nada mais apresentam, pois, que estas afirmações opostas: um limite é (eine Grenze ist) e o limite só é de fato um limite superado (aufgehobene); o limite tem sempre um para além com o qual se mantém em relação (in Beziehung steht), em direção ao qual deve ser transgredido, mas onde um tal limite, que não o é, ressurge. (HEGEL apud DERRIDA, 1991, p. 5)

Para pensar uma outra possibilidade de escrita, em relação de différance 1 àquela fundamentada na estrutura representacional, Derrida propõe (1991) a concepção de escritura na condição de disseminação, sem, entretanto, partir da base hegeliana. O limite, que sempre é transposto na estrutura dialética através da antítese construída para formulação de uma nova síntese, é, através da descrição de Derrida (1991), colocado em suspensão, para pensar uma possibilidade do que está para além desse limite, sem, entretanto, excluí-lo.

A escritura, dessa forma, não supera o limite, deixando-o para trás, pois o signo escrito é repetível e iterável (caminha em direção a outridades). A escritura traz para o agora, representa e performa. A escritura como acontecimento tem a força de repetição, de representação, mas ao 
mesmo tempo instaura o movimento que lança para o outro possibilidades de significação. A linguagem é feita de dois tipos de enunciados: os constatativos (concepção clássica concebida como "descrição" verdadeira ou falsa dos fatos) e os performativos. Derrida (1991) não trabalha com um limite dialético entre eles, mas produz uma ferida ou rasura que coloca o limite em suspensão, para pensar que a escritura não apenas constata, mas performa.

Um dos conceitos realçados por Derrida para pensar o performativo na escritura é a ideia de ausência. Na perspectiva tradicional, escreve-se para comunicar-se com alguém ausente. $\mathrm{Na}$ ausência do emissor ou do destinatário, a escrita — que se separa dele e continua a produzir efeitos para além de sua presença e do seu querer-dizer - é continuamente modificada na representação e em sua proposta comunicativa. Escrever, re-presen-tar (presente novamente), supre regularmente a presença perdida no momento da escrita. No entanto, para Derrida (1991), a ausência regula um outro conceito operatório: o rastro. Pensado numa concepção clássica, traçar significaria "exprimir", "representar", "evocar" ou "tornar presente":

O signo nasce ao mesmo tempo que a imaginação e a memória, no momento em que é requerido pela ausência do objeto na percepção presente ("A memória, como vimos, consiste apenas no poder de evocar os signos das nossas ideias, ou das circunstâncias que as acompanharam [...]"). (DERRIDA, 1991, p. 355)

Rastrear ou tornar presente pressupõe, a partir da tradição clássica, assegurar a presença na ausência, pois propõe "uma teoria do signo como representação da ideia que já é ela própria a coisa percebida” (DERRIDA, 1991, p. 356). Para Derrida (1991), entretanto, dá-se que,

[...] na medida em qualquer signo, tanto na 'linguagem de ação' quanto na linguagem articulada [...], supõe uma certa ausência [...], é preciso que a ausência no campo da escrita seja um tipo original se se pretende reconhecer [...] especificidade ao signo escrito. (DERRIDA, 1991, p. 356).

Como o signo escrito avança na ausência de um destinatário, para que ele permaneça legível, é preciso que seja iterável (ideia de repetição que é associada ao conceito de alteridade). "Uma escrita que não seja estruturalmente legível — iterável — para além da morte ou ausência do destinatário não seria uma escrita" (DERRIDA, 1991, p. 357).

Dito de outro modo, qualquer escrita deve poder funcionar na ausência radical de qualquer destinatário, de modo que essa ausência não seja uma modificação contínua da presença, mas uma ruptura. Tem-se então a morte ou possibilidade da morte do destinatário inscrita na estrutura mesma da marca, e a destruição do contexto como protocolo do código:

O que vale para o destinatário vale também, pelas mesmas razões, para o emissor ou para o produtor. Escrever é produzir uma marca que constituirá uma espécie de máquina por sua vez produtiva, que a minha desaparição futura não impedirá de funcionar e de dar, de se dar a ler e a reescrever. Quando digo "a minha desaparição futura", é para tornar essa proposição mais imediatamente aceitável. Devo poder dizer a minha desaparição simplesmente, a minha não-presença em geral, e, por exemplo, a não-presença do meu querer-dizer, da minha intenção-de-significação, do meu querer-dizer, do meu querer-comunicar-isto, na emissão ou na produção da marca. Para que meu escrito seja um escrito, é necessário que continue a "agir" e ser legível mesmo se o que se chama o autor do escrito não responde já pelo que escreveu, pelo que parece ter assinado, quer esteja provisoriamente ausente, quer esteja morto ou que em geral não tenha mantido a sua intenção ou atenção absolutamente atual e presente, a plenitude do seu querer-dizer, mesmo daquilo que parece ser escrito em "seu nome". (DERRIDA, 1991, p. 357)

A escrita como condição iterativa é o que possibilita, de acordo com Derrida (1991), a isenção de qualquer responsabilidade ou autoridade absoluta, da consciência ou intenção como autoridade e a ruptura com o horizonte da comunicação das consciências ou das presenças e com o 
transporte do "querer-dizer". Em última instância, fala-se aqui do desvio do horizonte das polissemias para a disseminação - que não segue ordem ou campo delimitado, mas flui a partir da propagação.

Como ponto de atravessamento do conceito de escrita, Derrida (1991) traz o performativo para discussão:

Diferentemente da afirmação clássica, do enunciado constatativo, o performativo não tem o seu referente (mas aqui esta palavra não convém sem dúvida, e constitui o interesse da descoberta) fora de si ou, em todo caso, antes de si e face a si. Não descreve qualquer coisa que exista fora da linguagem e antes de si. Produz ou transforma uma situação, opera [...]. (DERRIDA, 1991, p. 363)

O performativo é uma "comunicação" que não se limita essencialmente a transportar um conteúdo semântico já construído e vigiado por um objeto de verdade [...] (DERRIDA, 1991, p. 363)

Ao tentar definir o performativo, Austin (apud DERRIDA, 1991) tentou em vão fixar a pertinência e o rigor como critérios:

Para o mostrar, devo considerar permanentemente um valor de contexto, e mesmo de contexto exaustivamente determinável, justamente ou teologicamente; e a longa lista dos fracassos (infelicities) de tipo variável que podem afetar o acontecimento do performativo regressa sempre a um elemento do que Austin chama o contexto total. Um desses elementos essenciais - e não um entre outros - permanece classicamente a consciência, a presença consciente da intenção do sujeito falante perante a totalidade do seu ato locutório. (DERRIDA, 1991, p. 364)

Nessa perspectiva, a presença consciente dos locutores ou receptores na realização do performativo "implica [...] que nenhum resto escape à totalização presente" - "nenhuma disseminação [...] escape ao horizonte da unidade do sentido" (DERRIDA, 1991, p. 364). Para garantir o sucesso do enunciado do performativo, essas seriam as condições traçadas por Austin (apud DERRIDA, 1991):

Através dos valores de "convencionalidade", de "correção" e de "integralidade" que intervém nessa definição, encontramos necessariamente os de contexto exaustivamente definível, de consciência livre e presente na totalidade da operação, de querer-dizer absolutamente pleno e senhor de si: jurisdição teológica de um campo total cuja intenção permanece o centro organizador. (DERRIDA, 1991, p. 365)

Para Derrida (1991), entretanto, a oposição sucesso/fracasso da ilocução aparece como insuficiente. Sua teoria, em vez disso, propõe uma elaboração geral e sistemática da estrutura da enunciação que deixaria de lado a alternância sem fim entre essência e acidente.

Um enunciado performativo poderia ser conseguido se a sua formulação não repetisse um enunciado "codificado" ou iterável, dito de outro modo, se a fórmula que pronuncio para abrir uma sessão, lançar um barco ou casamento não fosse identificável de qualquer maneira como "citação". Não que a citacionalidade seja aqui do mesmo tipo que numa peça de teatro, uma referência filosófica ou a recitação de um poema. É por isso que existe uma especificidade relativa, como diz Austin, uma "pureza relativa" dos performativos. Mas esta pureza relativa não se eleva contra a citacionalidade ou iterabilidade, mas contra outras espécies de interação no interior de uma iterabilidade geral que faz estragos na pureza pretensamente rigorosa de qualquer acontecimento de discurso ou de qualquer speech act. É preciso [...] construir uma 
tipologia diferencial de formas de iteração [...]. Nessa tipologia, a categoria de intenção não desaparecerá, terá o seu lugar, mas, a partir deste lugar, não poderá já comandar toda a cena e todo sistema de enunciação. Sobretudo, teremos agora que lidar com diferentes tipos de marcas ou cadeias de marcas iteráveis e não com uma oposição entre os enunciados citacionais, por um lado, e os enunciados acontecimentos singulares e originais, por outro. (DERRIDA, 1991, p. 368-369)

Pode-se pensar que, a partir da condição de iteração, a intenção que anima a enunciação não será nunca de todo presente. Desse modo, o seu contexto não pode ser determinado, já que para isso seria necessário que a intenção consciente fosse totalmente presente e transparente. A différance, a ausência da intenção na enunciação do performativo, não exclui, de acordo com Derrida (1991), o efeito de presença e de acontecimento discursivo.

A partir dessas reflexões é possível afirmar que aquele que fala em enunciados performativos é o autor-tradutor, ou o performer-tradutor. Entretanto, essa assinatura, que também se constitui enquanto forma iterável, separa-se da intenção presente e única de sua produção para causar um efeito. Essa ruptura, nomeada por Derrida (1991) de disrupção da presença na marca, é o acontecimento ou nascimento da escritura - que, "através de um gesto duplo, uma dupla ciência, uma dupla escrita, pratic[a] uma reviravolta da oposição clássica $e$ um deslocamento geral do sistema" (DERRIDA, 1991, p. 372). Em síntese, a escritura na condição de disseminação não se reduz a uma polissemia, pois não se trata de uma "descodificação hermenêutica" de verdades, mas instaura possibilidades que se disseminam através da experiência.

\section{PERFORMANCE: CORPO E CONJUNTURA}

Nossa proposta aqui é, pois, considerar a cena como um processo tradutório. Por meio das performances, os corpos constroem dispositivos para que se tornem aquilo que são: no vazio da possibilidade de existência como sujeito ativo do mundo, as performances funcionam como formas estéticas e políticas de recriação de existência.

Graciela Ravetti (2003) caracteriza o performático como o ato visível apenas ao olho, também performático, de quem compartilha a experiência. Sendo um percurso que revela experiências que vão do âmbito pessoal ao comunitário (e vice-versa), o trânsito da performance é pensado como um impulso que ativa resíduos ou traços culturais e subjetivos, traços que se percebem como restos de algo maior. Portanto a experiência é tomada por Ravetti (2003) como algo reproduzível através da iterabilidade e das relações com o passado (memória), ao mesmo tempo em que relê o presente e transmite o futuro.

Nesse mesmo fluxo de pensamento, Diana Taylor (2013) propõe a performance como forma de preservação e de transmissão da memória. Ao estudar o grupo de teatro peruano Yuyachkani, a autora pensa as relações do performático a partir do nome atribuído à companhia, que significa em quéchua "'estou pensando', 'estou lembrando', 'eu sou o seu pensamento" (TAYLOR, 2013, p. 264). Isso se traduz em uma perspectiva de performance que incorpora a memória e o conhecimento, tornando fluido o limite que separa os sujeitos pensantes e os sujeitos do pensamento.

Nessa perspectiva, o duplo elo entre corpos é construído a partir de relações de alteridade: "eu" e "você" são "um produto das experiências e memórias um do outro, do trauma histórico, do espaço encenado, da crise sociopolítica" (TAYLOR, 2013, p. 264). Essa memória incorporada, segundo Taylor (2013), distingue-se do arquivo, pensado como um recurso permanente e tangível ao longo do tempo. O pensamento organizado do arquivo diferencia-se da noção transitiva de memória incorporada presente na performance, pois implica uma compreensão relacional — a ser suplementada pelo outro - e não individualista de subjetividade: "O 'eu' que lembra é simultaneamente ativo e passivo (sujeito pensante/sujeito do pensamento)" (TAYLOR, 2013, p. 265).

Nesse sentido, podemos pensar o gesto de reinvenção de si como novas formas que operam para além de "uma longa tradição [que] [...] v[ê] como conhecimento incorporado tudo aquilo que desaparece por não poder ser contido ou recuperado por meio do arquivo" (TAYLOR, 2013, p. 268). Sendo assim, o corpo pode ser um arquivo: em cena, a memória se faz presente a partir de sua 
relação de alteridade e movimentação, "reconstituindo-se - transmitindo memórias, histórias e valores comuns de um grupo ou geração para os seguintes" (TAYLOR, 2013, p. 268).

A noção de corpo como arquivo é pensada por Ravetti (2003) como uma espécie de transarquivo, corpus amplo e versátil "cultivado por escritores(as) que fazem uso de seu corpo, de seu saber corporal, para registrar e comunicar esse saber [...] performático" (RAVETTI, 2003, p. 40). Seria:

[...] uma assinatura plural, aquela que reúne a um e mais assinantes, anônimos em sua individualidade mas identificáveis em sua grupalidade. Uma assinatura floral, ramificada, performática. Então o arquivo performático estaria chamando a uma assinatura e a um consignatário dessa assinatura, aquele que traz consigo não só uma denominação - o representante —, mas também um saber cuja possessão the foi garantida pelo grupo. A assinatura performance seria o que diferenciaria essas práticas - performáticas - das demais; a consignação entrega-se a quem se responsabiliza por essa performance: como executante, como observador, como testemunha, como teórico, como crítico ou cumprindo mais de uma dessas funções. O consignante compromete seu corpo ou sua mirada (que também é seu corpo) e projeta-se naquilo que executa. Às vezes, um texto escrito. (RAVETTI, 2003, p. 38)

Propomos pensar aqui que estas assinaturas são a marca do performer-tradutor. As performances suspendem os limites do representativo, pois, ao mesmo tempo em que apresentam um campo de memória coletiva - a experiência atrelada à uma conjuntura histórico-política instauram e lançam para o espectador possibilidades múltiplas de significação. De modo semelhante, Ravetti (2003) afirma que sem transgressão - subversão e insubordinação aos mandatos sociais e políticos - não há performance. Performar é instaurar uma possibilidade de resistência e de escrita de si que transgride e ressignifica o trauma conjuntural através do corpo. Essas marcas articulam experiências através de uma autoinscrição advinda da cena, que simultaneamente ganha contornos singulares - e inscreve um gesto que funciona dentro, contra e a favor 2 do próprio tempo, denotando a natureza política e intempestiva do gesto performático.

\section{TRADUÇÃO PERFORMÁTICA: TEMPO E INTEMPESTIVIDADE}

De acordo com Nietzsche (2001), a verdade e a mentira são construções advindas do que ele intitula como vida no rebanho, bem como da linguagem que corresponde a essa vida, a partir da utilidade dessa linguagem para manter a paz dentro de determinada comunidade. Para Nietzsche (2001), o homem chama de verdade aquilo que o conserva na comunidade; e os gestos e discursos que manifestam uma experiência individual, em oposição ao rebanho, trariam perigo para aqueles que assim se mostram.

De fato, aquilo que daqui em diante deve ser a verdade é então fixado, quer dizer, é descoberta uma designação uniformemente válida e obrigatória das coisas, e a legislação da linguagem vai agora fornecer também as primeiras leis da verdade, pois, nesta ocasião e pela primeira vez, aparece uma oposição entre verdade e mentira. (NIETZSCHE, 2001, p. 9-10)

Nietzsche (2001) qualifica ainda a verdade como uma soma de relações humanas realçadas, transpostas e ornamentadas pela poesia e pela retórica; que, após um longo uso (repetição), parecem estáveis e canônicas aos olhos de um povo. De acordo com ele, o esquecimento do mundo primitivo das metáforas foi a cristalização e a esclerose do mar de imagens que constitui a capacidade da imaginação do indivíduo, na sua condição de sujeito criador e artista; de modo que, ao transpor os muros desta crença que o aprisiona, o sujeito ganharia consciência de si.

Ele está livre então do sinal da servidão: empenhado habitualmente na sombria tarefa de indicar a um pobre indivíduo que aspira à existência o caminho e os meios de alcançá-lo, extorquindo para o seu senhor a presa e o produto do saque, ele agora 
tornou-se o senhor e pode então apagar do rosto a expressão da indigência. Tudo o que faz daí por diante, comparado com a maneira como agia antes, envolve a dissimulação, assim como o que fazia antes envolvia a distorção. Ele imita a vida do homem, mas a toma por uma boa coisa e parece estar com isso verdadeiramente satisfeito. Esta armadura e este chão gigantesco dos conceitos, aos quais o homem necessitado se agarra durante a vida para assim se salvar, não é para o intelecto liberado senão um andaime e um joguete para suas obras de arte mais audaciosas; e quando ele o quebra, o parte em pedaços e o reconstrói juntando ironicamente as peças mais disparatadas e separando as peças que se encaixam melhor, isto revela que ele não precisa mais daquele expediente da indigência e que não se encontra mais guiado pelos conceitos, mas pelas intuições. (NIETZSCHE, 2001, p. 20)

A partir da noção de sujeito como agência, é possível, portanto, pensar a performance como um mecanismo de tradução através do agora. Ou seja, através da cena, a performance cria rasuras em discursos oficiais e em estruturas de ordenamento cronológico - aderindo e ao mesmo tempo tomando distância de seu tempo — marca da intempestividade (Nietzsche, 2003) da tradução performática.

[...] pois não saberia que sentido teria a filologia clássica em nossa época senão o de atuar nela de maneira intempestiva - ou seja, contra o tempo, e, com isso, no tempo, e, esperemos, em favor de um tempo vindouro. (NIETZSCHE, 2003, p. 7)

Pertence verdadeiramente a seu tempo, é verdadeiramente contemporâneo, aquele que não coincide perfeitamente com este, nem está adequado às suas pretensões e é, portanto, nesse sentido, inatual; mas, exatamente por isso, exatamente através desse deslocamento e desse anacronismo, ele é capaz, mais do que os outros, de perceber e apreender o seu tempo. (AGAMBEN, 2013, p. 58-59)

O intempestivo de Nietzsche (2003), assim como o contemporâneo de Agamben (2013) funcionam como forma de compreensão e releitura de verdades históricas. Em diálogo com a intempestividade de Nietzsche (2003), Agamben (2013) nomeia o contemporâneo como aquele que mantém fixo o olhar no seu tempo para perceber o escuro. De acordo com ele, todos os tempos são obscuros para quem observa a contemporaneidade. O contemporâneo, entretanto, é aquele capaz de "escrever mergulhando a pena nas trevas do presente." (AGAMBEN, 2013, p. 63). No mesmo sentido, Nietzsche (2003) afirma que "a todo agir liga-se um esquecer: a vida não diz respeito à luz, mas também à obscuridade" (NIETZSCHE, 2003, p. 9).

O a-histórico é similar a uma atmosfera que nos envolve e na qual a vida se produz sozinha, para desaparecer uma vez mais com a aniquilação dessa atmosfera. É verdade: somente pelo fato de o homem limitar esse elemento a-histórico pensando, refletindo, comparando, separando e concluindo; somente pelo fato de surgir no interior dessa névoa que nos circunda um feixe de luz muito claro, relampejante, ou seja, somente pela capacidade de usar o que passou em prol da vida e de fazer história uma vez mais a partir do que aconteceu, o homem se torna homem. (NIETZSCHE, 2003, p. 12)

O escuro não é, portanto, um conceito privativo, a simples ausência da luz, algo como uma não-visão, mas o resultado da atividade das off-cells, um produto da nossa retina. Isso significa, se voltarmos agora à nossa tese sobre o escuro da contemporaneidade, que perceber esse escuro não é uma forma de inércia ou de passividade, mas implica uma atividade e uma habilidade particular que, no nosso caso, equivalem a neutralizaras luzes que provêm da época para descobrir suas trevas, o seu escuro 
especial, que não é, no entanto, separável daquelas luzes. (AGAMBEN, 2013, p. 63)

Perceber o escuro do seu tempo - como alguém que manuseia as dobras de um tecido e brinca com o visível e o invisível presentes na superfície rugosa - é ser capaz de dançar por entre as ausências do instante através da potência e da capacidade de reinscrição. A performance traduz o tempo a partir de sua intempestividade: como corpo que "esquece a maior parte das coisas para fazer uma apenas, corpo do instante, que só conhece um direito, o direito daquilo que vir a ser agora." (NIETSZCHE, 2003, p. 13).

Compreendam bem que o compromisso que está em questão na contemporaneidade não tem lugar simplesmente no tempo cronológico: é, no tempo cronológico, algo que urge dentro deste e que o transforma. E essa urgência é a intempestividade, o anacronismo que nos permite apreender o nosso tempo na forma de um "muito cedo" que é, também, um "muito tarde", de um "já" que é, também, um "ainda não". E, do mesmo modo, reconhecer nas trevas do presente a luz que, sem nunca poder nos alcançar, está perenemente em viagem até nós. (AGAMBEN, 2013, p. 65-66)

A potência do agora toca o passado como história contanto que, segundo Nietzsche, "aprendamos cada vez melhor exatamente isso: a impulsionar a história a serviço da vida!" (NIETSZCHE, 2003, p.16).

\section{REFERÊNCIAS}

AGAMBEN, Giorgio. O que é o contemporâneo. In: . O que é o contemporâneo e outros ensaios. Tradução de Vinícius Nicastro Honesko. Chapecó: Argos, 2013, p. 55-73.

DERRIDA, Jacques. Assinatura acontecimento contexto. In: Margens da filosofia. Tradução de Joaquim Torres Costa, António M. Magalhães; revisão de técnica de Constança Marcondes Cesar. Campinas: Papirus, 1991. p. 5, p. 349-373.

UFMG, 2006

Torres de Babel. Tradução de Junia Barreto. Belo Horizonte: Editora

JAKOBSON, Roman. Lingüística e Comunicação. São Paulo: Editora Cultrix e Universidade de São Paulo, 1969.

NIETZSCHE, Friedrich. Verdade e mentira no sentido extramoral. Comum, Rio de Janeiro, v. 6, n. 17, p. 5-23, jul./dez. 2001.

Segunda consideração intempestiva: da utilidade e desvantagem da história para a vida. Tradução de Marco Antônio Casanova. Rio de Janeiro: Relume Dumará, 2003. p. 5-17.

OTTONI, Paulo. A prática da diferença. In.: Tradução: a prática da diferença. São Paulo: Editora Unicamp, 2005.

Unicamp, 2005.

. Tradução Manifesta: double bind e acontecimento. São Paulo: Editora da

RAVETTI, Graciela. Performances escritas: o diáfano e o opaco da experiência. Tradução de Melissa Gonçalves Boechat e Karla Fernandes Cipreste. In: HILDEBRANDO, Antonio; NASCIMENTO, Lyslei; ROJO, Sara (Org.). O corpo em performance: imagem, texto, palavra. Belo Horizonte: NELAP/FALE/UFMG, 2003. p. 31-59.

RODRIGUES, Cristina Carneiro. Ambivalência e conflito. In: . Tradução e diferença. São Paulo: Editora UNESP, 2000. p. 163-215.

TAYLOR, Diana. Encenando a memória traumática: Yuyachkani. In: $\mathrm{O}$ arquivo e $\mathrm{o}$ repertório: performance e memória cultural nas Américas. Tradução de Eliana Lourenço de Lima Reis. Belo Horizonte: Editora UFMG, 2013. p. 263-294. 


\section{NOTAS}

1 Como lembra Carneiro (2000), a différance trata da " "produção do diferir, no duplo sentido dessa palavra', que supõe que não haja síntese possível e que nenhum elemento possa estar presente em si e referendo apenas a si próprio (Derrida, 1967/1973, p. 29). O verbo 'diferir', como différer, tanto pode significar 'adiar, procrastinar, retardar', quanto 'divergir, discordar', 'ser diferente', 'distinguir-se'. Assim, a diferência envolve tanto a diferença quanto o adiamento, tanto 'intervalo, distância' quanto 'uma demora, um retardamento', tanto espaço quanto tempo (Derrida, 1972/1991b, p. 39). A diferência não é presença, pois um sistema em que os signos se referem apenas a outros signos, há um infinito processo de adiamentos e remissões, nunca há o encontro de uma presença exterior à linguagem.” (CARNEIRO, 2000, p. 197-8).

2 Referência às ideias de Nietzsche (2003) sobre o intempestivo. 